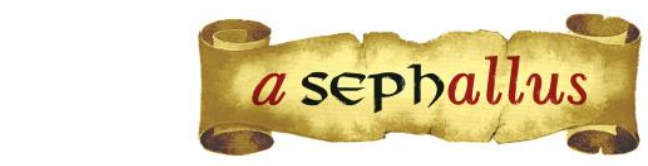

Revista aSEPHallus de Orientação Lacaniana

Núcleo Sephora de Pesquisa sobre o Moderno e o Contemporâneo

ISSN $1809-709 \mathrm{X}$

\title{
A clínica reorientada pela pesquisa na pós-graduação
}

Tania Coelho dos Santos

Pós-doutorado no Departamento de Psicanálise de Paris VIII, Professor Associado, nível IV no Programa de Pós-graduação em Teoria Psicanalítica/UFRJ (Rio de Janeiro, Brasil) Pesquisadora do CNPQ nível 1 C. Presidente do Instituto Sephora de Ensino e Pesquisa de Orientação Lacaniana/ ISEPOL, Psicanalista Membro da École de La Cause Freudienne, da Escola Brasileira de Psicanálise e da Associação Mundial de Psicanálise,

Membro da Associação Universitária de Pesquisa em Psicopatologia Fundamental (Rio de Janeiro, Brasil)

E-mail: taniacs@openlink.com.br

Resumo: A realidade de fato do programa de pós-graduação em teoria psicanalítica nos conduziu a ir além da proposta inicial: a pesquisa teórica dos fundamentos epistemológicos desta disciplina. No início, o programa atendeu a demanda de psicanalistas em prática privada de conferir mais densidade teórica e refinamento clínico às suas respectivas formações em institutos, escolas e sociedades psicanalíticas. Depois dos anos 2000 uma grande quantidade de profissionais que praticam a psicanálise aplicada em instituições públicas tais como, saúde, educação e justiça e, algumas vezes, em instituições privadas chegaram ao nosso curso de mestrado e doutorado com a intenção de repensar suas práticas à luz da pesquisa rigorosamente conduzida em conformidade com a teoria da clínica psicanalítica. É deste universo que pretendo falar.

Palavras-chave: clínica, reorientada, pós-graduação, teoria psicanalítica

La clinique réorientée para la recherche dans les études post universitaires La réalité du programme d'études post universitaires em théorie psychanalytique nous a conduit à aller au-delà de la proposition initiale: la recherche théorique des fondements épistémologiques de cette discipline. Au début, le programme répondait à la demande des psychanalystes du secteur privé souhaitant conférer une densité plus théorique et un raffinement clinique à leurs formations respectives dans les instituts, les écoles et les sociétés psychanalytiques. Après les années 2000, un grand nombre de professionnels pratiquant la psychanalyse et appliqués dans des institutions publiques vouées a la santé, l'éducation et la justice et parfois dans des institutions privées ont rejoint nos cours de maîtrise et de doctorat dans le but de repenser leurs pratiques à la lumière de recherche rigoureusement menée conformément à la théorie de la clinique psychanalytique. C'est de cet univers que j'ai l'intention de parler.

Mots-clés: clinique, réorientée, post-gradué, théorie psychanalytique

The reorientation of the clinic towards research in postgraduate studies The reality of the graduate program in psychoanalytic theory led us to go beyond the initial proposal: the theoretical research of the epistemological foundations of this discipline. At first, the program met the demand of psychoanalysts in private practice to confer more theoretical density and clinical refinement to their respective formations in institutes, schools and psychoanalytic societies. After the 2000s a great number of professionals who practice applied psychoanalysis in public institutions with objectives such as health, education and justice and sometimes in private institutions have reached our masters and doctorate course with the intention of rethinking their practices in the light of research rigorously conducted in accordance with the theory of psychoanalytic clinic. It is this universe that I intend to explore.

Key-words: clinical, reorientated, postgraduate, psychoanalytic theory 


\title{
A clínica reorientada pela pesquisa na pós-graduação
}

\author{
Tania Coelho dos Santos
}

\section{Um tempo de hostilidades}

A fundação do programa de mestrado em teoria psicanalítica despertou uma forte hostilidade entre muitos psicanalistas que acreditavam que a psicanálise não podia ser ensinada na universidade. Faltava - é o que se dizia na época - ao ambiente acadêmico a transferência que caracteriza os laços entre os membros de uma sociedade de formação de psicanalistas.

Por parte dos pesquisadores em psicologia, a hostilidade se apresentava por meio do repúdio à pesquisa bibliográfica - considerada muito desatualizada - como era o caso, por exemplo, da "obsoleta" obra de Freud. Era incompreensível que se pudesse produzir conhecimento novo, revistando obras clássicas - em grande parte datadas do século XIX e início do XX - tais como: o já citado fundador da psicanálise e seus discípulos Melanie Klein, Ana Freud, Ferenczi, Abraham, Winnicott e outros como Jacques Lacan, Jean Laplanche ou André Green. A quem poderia interessar um trabalho de revisão e sistematização de bibliografia tão antiquada? Para que despender recursos públicos para remexer nos restos do passado em lugar de produzir conhecimento inédito, experimental, verdadeiramente científico.

A resposta é a seguinte. No início, o programa atendeu a demanda de psicanalistas em prática privada de conferir maior densidade teórica e refinamento clínico às suas respectivas formações em institutos, escolas e sociedades psicanalíticas. Nossos alunos eram, frequentemente, psicanalistas com grande experiência clínica que se queixavam de seus conhecimentos amplos, porém, assistemáticos. Ora, uma dissertação de mestrado permite justamente a elaboração de uma revisão da literatura, organizada, sistematizada e coerente para fins de ensino. Quando é bem sucedida, essa formalização do conhecimento amealhado ao longo de muitas leituras, permite que se produza uma problematização do conhecimento adquirido, conduzindo o futuro pesquisador a ir além de perguntas vagas e mal formuladas.

Tanto isso, que eu recordo aqui, é verdade que, em 1994, fundamos o programa de doutorado e tive a honra de orientar e levar à banca em 1998, a primeira tese de doutorado intitulada "A experiência do excesso: por uma revisão da loucura dos artistas" de autoria de Maria Clara Queiroz Corrêa. Psicanalista, entusiasmada pelo ensino, mas sem carreira universitária, produziu uma tese acerca da psicose de um fôlego admirável, contribuindo definitivamente - junto com muitos outros que a seguiram - para abalar a convicção - largamente difundida na época - de que os bons clínicos não eram bons teóricos. E vice-versa. Suspeitava-se de que intelectuais, professores, pesquisadores não eram sensíveis e afetivos. Acreditava-se piamente - antes que o ensino de Lacan contrariasse essa crença - que a psicanálise era uma prática relacionada à exposição, acolhimento e experimentação afetiva. Quanto mais se chorava em análise, mais se 
estava perto do suposto objetivo de cura pelo extravasamento das emoções reprimidas. Era a cultura do pathos.

Acredito que contribuímos para construir uma nova conviç̧ão: a de que a psicanálise é uma prática teórica e que uma coisa não vai sem a outra. Certamente, esta orientação, deve muito a Jacques Lacan, psicanalista que nos ensinou a reconhecer que uma prática analítica é um "tratamento do real pelo simbólico".

Destaco dois sintomas dessa relação conflituosa entre razão e afeto. 0 primeiro eu descreveria assim. A orientação epistemológica dominante na linha de pesquisa do programa baseava-se na afirmação de que a "pulsão está fora da linguagem". Um dilema com forte coloração épica atravessava a metodologia hegemônica: o embate da força versus a representação. Este tema me causou embaraços sérios em 1989, no momento de aderir ao grupo fundador do mestrado, quando ele ainda dava seus primeiros passos. Perplexa e confusa diante dessa dissociação entre razão e afeto fiz um sintoma. Passei dez anos ensinando nossos alunos a ler o "Seminário da Angústia", de Jacques Lacan. Eu encontrava assim uma forma altamente sintomática de reagir, defendendo que a pulsão não se encontra fora da linguagem. A angústia não é sem objeto, o objeto $a$ é um significante em vias de advir, não está necessariamente fora da linguagem. $\mathrm{O}$ objeto antecipa o advento do sujeito inconsciente. Por esta razão ele é justamente aquilo que é estruturado pela linguagem, não é uma força pulsional fora da representação.

Ao tomar como orientação na minha pesquisa o afeto de angústia que sinaliza a presença do real, eu manifestava minha aposta. No que se refere à pulsão, não haveria nada a buscar mais além deste afeto de angústia que manifesta a presença do objeto $a$. A manifestação afetiva não é o que está fora da linguagem. A manifestação afetiva é o que resta do aparelhamento do corpo pela linguagem. Não existe força pura, somente resto. $O$ objeto $a$ é o nome lacaniano deste resto. Ele é o nome da causa do desejo, do objeto em jogo no gozo do fantasma e, sobretudo, do objeto da angústia. A angústia não é sem objeto. $A$ força não é sem a representação. $O$ ensino na universidade não é sem a clínica. Sem ela, ele se transforma em filosofia psicanalítica. Não há razão sem afeto. Não há afeto sem razão. Defendo isso na orientação de minha prática como analista e em todas as práticas que supervisiono.

Para concluir, acredito que se não nos tornamos filósofos psicanalíticos foi porque as urgências da realidade social, definitivamente, bateram à nossa porta exigindo mais consideração da teoria pela prática clínica. A psicanálise aplicada impôs-se como exigência de trabalho feita à universidade em consequência de sua relação ao corpo social.

\section{Rumo à prática da psicanálise fora do divã}

A realidade de fato das mutações do laço social bateu à porta do programa de pósgraduação em teoria psicanalítica. Foram os sintomas de difícil classificação - nem neuróticos, nem psicóticos estritamente - que comecei a observar dentro e fora do consultório me levaram a buscar 
um pós-doutorado em Paris, no início dos anos 2000. A prática no divã tendia a dar lugar ao tratamento em instituições de adições e compulsões como toxicomania, obesidades, anorexias e erotomanias, os novos sintomas pós-modernos, enfim. Buscando aprofundar o diagnóstico e o tratamento destes novos sintomas, encontrei uma nova abordagem: a clínica continuísta. Desse novo ponto de vista, os sintomas podiam ser classificados como freudianos - estruturados como a linguagem e que podem ser decifrados pelo discurso ou a interpretação - ou, simplesmente como efeito do excesso pulsional rebelde à tradução em discurso inconsciente por meio da interpretação.

Passei a encarar a psicanálise pura e psicanálise aplicada como respostas a sintomas diferentes: modernos e pós-modernos. Assim, a psicanálise aplicada era algo além, simplesmente, de práticas psicanalíticas fora do divã. Ela era uma resposta à desregulação do gozo, própria aos novos sintomas na contemporaneidade, e resultava do entendimento de que interpretação pelo sentido não era a única, nem mesmo a melhor estratégia no tratamento dos sintomas de difícil classificação. Essa mudança de perspectiva foi essencial à minha formação, à minha atividade de pesquisa e ao meu trabalho como orientadora de pós-graduação.

Depois dos anos 2000 uma grande quantidade de profissionais que praticam a psicanálise aplicada em instituições públicas tais como, saúde, educação e justiça e, algumas vezes, em instituições privadas, chegaram ao nosso curso de mestrado e doutorado com a intenção de repensar suas práticas à luz da pesquisa rigorosamente conduzida em conformidade com a teoria da clínica psicanalítica. É deste universo de experiências na pós-graduação que pretendo falar.

Começo enaltecendo a importância de algumas das teses de doutorado que orientei para a reconfiguração do campo de pesquisa e que me permitiram incluir problemas relacionados com a aplicação da psicanálise ao tratamento da violência, do ato infracional e dos atos criminosos. Explico. Eu sempre fui uma psicanalista em prática privada. Mas, comecei a ser procurada por psicanalistas que exerciam também sua prática em instituições. Foi pioneira neste sentido a tese de doutorado de Maria Angélia Teixeira acerca da violência, em 2004. Ela se perguntava se a violência era ainda uma forma de laço social ou se configurava uma ruptura. Incentivei-a a trazer para a pesquisa sua experiência com analisandos traumatizados por acontecimentos como sequestro, tortura e estupro durante assaltos violentos. Pude avaliar o quanto os analistas resistem a abordar diretamente aquilo que a clínica ensina. Isso os perturba profundamente, mas os condena ao silêncio e ao segredo. Trazer ao debate universitário a violência cotidiana, sem ferir a confidencialidade, foi um grande desafio.

Maria José Gontijo, praticante de uma clínica no PAIPJ/MG com loucos infratores, veio interrogar a relação entre culpabilidade e castigo dos atos criminosos, agressões e violência. Sua tese foi uma ocasião inestimável para que eu pudesse estabelecer com clareza a orientação para a responsabilidade que se coloca mais além do ato criminoso. Com Lacan, aprendemos a "irrealizar" o crime - abordando-o por meio de sua significação simbólica inconsciente - sem "irrealizar" o criminoso, a quem é preciso conduzir rumo à responsabilidade pelo seu ato. Escapávamos assim 
ao dilema que divide o praticante ante 0 ato criminoso, embaraçado diante do problema da culpabilidade, tratando-o ora como monstro, ora como vítima da sociedade.

Também a tese de Jorge Forbes, em 2007 me permitiu retonar ao tema das relações entre inconsciente e responsabilidade. Em nossa abordagem dos sintomas, discursos e laços sociais no século XXI, não existe nenhuma via mais promissora para enfrentar a tendência hegemônica à vitimização e desresponsabilização.

Em 2005, pude acompanhar Christiane Zeitoune, psicóloga no DEGASE, numa pesquisa acerca das causas do ato infracional. Embora eu fosse inexperiente neste terreno, ousei sugerir um novo caminho. Em lugar de buscar o declínio, a ausência e a omissão da função paterna como causa de uma suposta precariedade identificatória, sugeri que investigássemos através da rica casuística do DEGASE, a importância dos impasses sexuais na adolescência como causa da passagem ao ato infracional. Uma grande quantidade de exemplos nos permitiram verificar que o traumatismo do reencontro com o objeto na puberdade, pode precipitar condutas infracionais. A pesquisa universitária demonstrou assim que pode oferecer contribuições originais.

Concluo destacando a importância que o trabalho de orientação de tantas pesquisas originais para a minha formação como psicanalista. Só posso agradecer aos meus ex-orientandos que hoje são membros do ISEPOL - Cristina Antunes, Rosa Guedes, Patricia Mattos, Douglas Abreu, Jaqueline Silva, Flávia Garcia de Oliveira, Fernanda Queiroz, Valeria Wanda, e Erly Alexandrino - pela confiança que depositaram no ensino e na transmissão que pude desenvolver graças a estes preciosos laços transferenciais.

E eu não poderia deixar de mencionar a colaboração efetiva com pós-doutorandos sob minha supervisão, como Anderson Sant' Anna, Jesus Santiago, Márcia Rosa, Ana Lydia Santiago e Angélica Tironi, que me ajudaram a constituir em 2006 um Grupo de Trabalho na ANPEPP onde a causa da pesquisa em psicanálise encontra suas consequências e muitos novos parceiros como o colega Antônio Teixeira.

\section{Referências bibliográficas}

Coelho dos santos, T. (2001). Quem precisa de análise hoje? São Paulo: Bertrand Brasil.

Coelho dos santos, T. (2004a). O que não tem remédio remediado está! In: Revista Latinoamericana de psicopatologia Fundamental, vol. VII, n. 1, 2004.

Coelho dos santos, T. (2004b). Le sacré dans la gauche et dans la pratique lacanienne in: Lettre Mensuelle de l'École de la cause freudienne. Paris: França, v. 233, p. 1-32.

Coelho dos santos, T. (2005a). A prática lacaniana na civilização sem bússola. In: COELHO DOS SANTOS, T. (org.). Efeitos terapêuticos na psicanálise aplicada. Rio de Janeiro: Contra capa, p. 61-92.

Coelho dos santos, T. (2005b). Sinthoma: corpo e laço social, Rio de Janeiro: Ed. Sephora/UFRJ. COELHO DOS SANTOS, T. (2005b). O sinthoma e a insígnia: fantasia ou caráter? Latusa, Rio de 
Janeiro: EBP- RJ, n. 10, p. 37-53.

Coelho dos santos, T. (2005c). A psicopatologia psicanalítica de Freud à Lacan. In: Revista Pulsional de Psicanálise, São Paulo, v. XVIII, n. 183, p. 74-81, 2005.

Coelho dos santos, T. (2006). A ciência e a verdade na formação do analista lacaniano.In: Acheronta, n. 22

Coelho dos santos, T. et al. (2006a). Se todo gordo é feliz, a obesidade é um sintoma ou uma solução? In: Bastos, Angélica (org.). Psicanalisar hoje. Rio de Janeiro: Contracapa.

Coelho dos santos, T. (2006b). O psicanalista é um sinthoma. Latusa, Rio de Janeiro: EBP- RJ, n. 11, p. $57-72$

Coelho dos santos, T. e ZUCCHI, m. (2007a). Estrutura e gozo: os novos sintomas como solução na neurose e na psicose. In: Freire, A.B. (org.) Apostar no sintoma. Rio de Janeiro: Ed. Contracapa, 2007, p. 61-82.

Coelho dos santos, T. e SARTORI, A. P. (2007b). Loucos de amor! Neuroses narcísicas, melancolia e erotomania feminina. In: Tempo psicanalítico, n. 39, p. 13-34.

Coelho dos santos, T. (2007c). Lições sobre a queda do objeto a na experiência analítica in: Latusa, n. 12, EBP/RJ, pags. 47-58.

Coelho dos santos, T. (2007d). O real em cacos: o objeto a na experiência analítica, in:Revista de Psicologia Plural, FUMEC, pags. 121-132.

Coelho dos santos, T. (2008a). A política do psicanalista: o saber da psicanálise entre ciência e religião. In: Psicologia em Revista, vol. 14, n. 1, p. 63-82.

Coelho dos santos, T. (2008b). Ciência e clínica psicanalítica: sobre o estruturalismo. In: Estudos Lacanianos, Ano 1, Número 1, p. 187-199.

Coelho dos santos, T. (2008c). Entre tapas e beijos: a tragicomédia dos sexos Latusa, Rio de Janeiro: EBP- RJ, n. 13.

Coelho dos santos, T. (2008d). Pulsão estruturada como a linguagem pu aparelhada como lalíngua? In: Barros, Rita Manso e Elia, Luciano (orgs.) Estrutura e psicanálise. Rio de Janeiro: Companhia de Freud/UERJ.

Coelho dos santos, T. (2008e). Sinthoma: a arte de encarnar e sublimar o próprio sexo in: COUTINHO, M.A. e MELLO, M. (ogs.). Saber fazer com o real. Rio de Janeiro: Companhia das Letras/UERJ, 2008.

Coelho dos santos, T. (2008f). Finais de análise: sexuação e invenção. In: Tempo psicanalítico, n. 40, p. $105-120$.

Coelho dos santos, T. (2008g). A vacilação generalizada dos semblantes, in: Soubboutnik, O.M. e Soubbotnik, M. (orgs) ENLACES : psicanálise e conexões, PPGL/MEL PPGHIS/ES pags. 313-326.

Coelho dos santos, T.(org.). (2009a). Inovações no ensino e na pesquisa em psicanálise aplicada, Ed. 7 Letras, RJ.

Coelho dos santos, T. (2009b). A interpretação analítica do sinthoma. In: Nascimento, E. (org). 
Revista do Curso de Especialização da UFBA, 2009.

Coelho dos santos, T. (2009 c). Do saber exposto ao saber suposto e retorno: ensino, pesquisa e transmissão da psicanálise. In: Opção Lacaniana, n. 54, p. 83-94.

Coelho dos santos, T. (2009d). Semblante e discurso: estrutura e verdade na ciência e na psicanálise. In: Latusa: EBP-RJ, n. 14.

Coelho dos santos, T. (2009e). Não existe pecado do lado de baixo do equador? In: Cadernos de Psicanálise, Sociedade de Psicanálise da Cidade do RJ, (no prelo)

Coelho dos santos, T. (2009f). O imperativo de publicar: incitação á farsa ou estímulo à produtividade intelectual? In: Tempo Psicanalítico, n. 41.

Coelho dos santos, T. (2009g). Do desejo do analista ao analista parceiro-sinthoma. In: CuringaEBP/ MG, n. 27, 2009.

Coelho dos santos, T. (2009h). Sobre a clínica de orientação Lacaniana: dos impasses da sexuação à invenção do parceiro- sinthoma. In: Agora (PPGTP/UFRJ) vol. XII, p. 9-26.

Citacão/Citation: Coelho dos Santos, T. (mai. 2018 a out. 2018). A clínica reorientada pela pesquisa na pós-graduação. Revista aSEPHallus de Orientação Lacaniana, 13(26), 74-80. Disponível em www.isepol.com/asephallus. Doi: 10.17852/1809-709x.2019v13n26p74-80.

Editor do artigo: Tania Coelho dos Santos.

Recebido/Received: 03/01/2019 / 01/03/2019.

Aceito/Accepted: $12 / 03 / 2019$ / 03/12/2019.

Copyright: (C) 2019 Associação Núcleo Sephora de Pesquisa sobre o moderno e o contemporâneo. Este é um artigo de livre acesso, que permite uso irrestrito, distribuição e reprodução em qualquer meio, desde que o autor e a fonte sejam citados/This is an open-access article, which permites unrestricted use, distribution, and reproduction in any medium, provided the author and source are credited. 